\title{
Distant Relations
}

\section{The Affordances of Email in Interorganizational Conflict}

Bülow, Anne Marie; Lee, Joyce Y. H.; Panteli, Niki

Document Version

Accepted author manuscript

Published in:

International Journal of Business Communication

DOI:

$10.1177 / 2329488416633847$

Publication date:

2019

License

Unspecified

Citation for published version (APA):

Bülow, A. M., Lee, J. Y. H., \& Panteli, N. (2019). Distant Relations: The Affordances of Email in Interorganizational Conflict. International Journal of Business Communication, 56(3), 393-413. https://doi.org/10.1177/2329488416633847

Link to publication in CBS Research Portal

\section{General rights}

Copyright and moral rights for the publications made accessible in the public portal are retained by the authors and/or other copyright owners and it is a condition of accessing publications that users recognise and abide by the legal requirements associated with these rights.

Take down policy

If you believe that this document breaches copyright please contact us (research.lib@cbs.dk) providing details, and we will remove access to the work immediately and investigate your claim. 


\section{Distant Relations: The Affordances of Email in Interorganizational Conflict}

\section{Anne Marie Bülow, Joyce Y. H. Lee and Niki Panteli}

Journal article (Post print version)

This article was originally published in International Journal of Business

Communication.

First published online February 26, २०16.

DOI: $\underline{10.1177 / 2329488416633847}$

Uploaded to Research@CBS: Januar २०१८ 


\title{
Distant Relations: The Affordances of Email in Interorganizational Conflict
}

\section{Anne Marie Bülow, Joyce Y. H. Lee, and Niki Panteli}

\begin{abstract}
This article explores the role of email in the ambiguous circumstances of an established international partnership that is developing into competition. Using the naturally occurring interaction of a longitudinal ethnographic study, we study the ensuing task and relationship conflicts through the communication medium. Results show that the conflict is facilitated by email, not as an unfortunate side-effect but as a strategic choice of distance, partly for passive protection but also for active control of the interaction. We use the results to chart the multiple situated identities of the communicators that are made salient in their virtual interaction. The double aspect of social and organizational contexts is shown to have an effect on different issues, such as organizational authority at the home organization, the buyer-supplier relationship, nonnative language use, and norms of communication style in the interaction.
\end{abstract}

\section{Keywords}

email, computer-mediated communication, affordances, workplace conflict, avoidance

Communication is not only the lifeblood of organizations but also of the connections with their stakeholders. In this article, we focus on an aspect of communication between two collaborating organizations which we consider underresearched, that of the strategic contribution of a particular medium. We argue that the affordances of the mundane, everyday exchanges of email are integral to the development of the complex relationship between the partners, particularly when, as in our case, the managers find themselves in ambiguous, shifting, and finally inimical relations

Much of the scholarly interest in recent years has been directed to other kinds of computer-mediated communication (CMC), as it supports distance work and virtual collaboration (Brown, Dennis, \& Venkatesh, 2010; Byron, 2008; Darics, 2014; Kupritz \& Cowell, 2011). However, even with the increasing availability of cloud collaboration tools and social media, email remains the most common medium in work settings (Jung \& Lyytinen, 2014; Lee \& Panteli, 2011).

Email is generally not considered a suitable tool for sensitive or complex tasks (Friedman \& Currall, 2003; Lee \& Panteli, 2010; Maruping \& Agarwal, 2004; Turnage, 2007; Turnage \& Goodboy, 2014). By adopting the theory of affordances, in this article, we explore some tactical options open to users of email that may explain its dominance in business communications; we argue that even for handling the complex tasks involved in business competition and conflict, email can be an effective and intentional choice. 
We support our argument on naturally occurring and exceptionally rich data from a field study. Over and above recorded messages, our data comprise interviews where users reflect on their media preferences, and observations with daily logs, detailing how the sequences of interaction are perceived at the office and how users' goals emerge in their organizational context. Access to the context of tasks and relationships allows us to contribute to what Walther (2013) called the "daunting question of how to isolate or even trace the causal influence of technology factors that lead to various outcomes" (p. 190).

Thus, we aim to make three contributions to research. First, we explore the overlap between the medium and the social interaction of the users. By following a not untypical interorganizational change in relationships over several months, we shall demonstrate the effect of social-level competition in the affected managers' communication, both laterally and upwards, by collected examples rather than by survey answers. Second, we study the overlap between the medium and organizational behavior. In isolating the several perspectives that are in play, we shall map a little-known relationship between $\mathrm{CMC}$ and strategic organizational purposes, involving control and protection. Third, we look at the overlap between the medium and conflict handling. By focusing on the affordances of the channel, we shall show how coexisting goals of cooperation and competition are pursued, not least though the several options for avoidance which lean media provide.

The fieldwork was undertaken in the Research and Development (R\&D) department of a high-tech company that we shall call "T-Tech," headquartered in Taipei, Taiwan. It followed a production project over 6 months, which was codeveloped with the company's chief supplier, here called "KN" in Seoul, South Korea. The project engendered communication consisting of sparse use of telephone calls, 5 people on two visits, and 735 emails.

Although the present study only concerns exchanges relating to the KN project, the handling of T-Tech's other projects is illustrative. For comparison, T-Tech's collaboration with its second biggest collaborator, which also had its headquarters in Seoul, and, like KN, a branch office in Taipei, involved similar design work. This collaboration produced a great deal of telephone contact, a total of 19 people on five visits and 190 emails.

At the time of the study, T-Tech and KN were becoming engaged in direct competition in the American market, and T-Tech found dealings with its supplier increasingly difficult. At the same time, T-Tech needed to nurse the relationship until its products were on the market. There were no such problems with the other collaboration. It is clear from the comparison of the email traffic in the two similar collaborations that it was only the more difficult relationship that managers preferred to handle via email. On this background, we set out to answer the following question:

Research Question: What are the affordances of email for users in conflictual interorganizational relationships?

In reviewing the theories that will serve as our guiding framework, we shall first consider theories that clarify the relationship between the medium and individuals and/or groups; and second, the relationship between the medium and conflict behavior in organizations.

\section{Theoretical Background}

Our study involves observation of a group of people who work in circumstances that will be recognizable to many international businesses. In developing the new products with international partners, they work for a company to which 
they are accountable in delivering results; this is their organizational context. Furthermore, they manage task and relationship goals both within the home group and across boundaries with the overseas partner in the established development group; this is their social context. Work groups of this kind are normally fuzzy over time, so that certain people have more day-to-day contact than others, and for different reasons, and never everyone at the same time. For communication purposes, these are challenging circumstances.

\section{Virtual Collaboration}

Scholarly interest in CMC has developed chiefly along two theoretical avenues, often summarized as "cues-filtered-out" theories (Culnan \& Markus, 1987) and "cues-filtered-in" theories (Walther \& Parks, 2002); for a summary of the first wave, see van den Hooff, Groot, and de Jonge (2005), and for a recent survey, see Walther (2013). One of the key terms for both directions is perceived distance, and for international business collaboration, the natural assumption is that distance is a disadvantage.

The "cues-filtered-out" theories are developed on the background of the seminal study by Daft and Lengel (1986), who found that communication was transmitted effectively in different channels for different purposes, and that face-to-face communication was richer in cues than asynchronous, text-based channels. Email, as a medium that lacks immediate feedback and nonverbal cues, is normally classified as a lean medium, not only in comparison with face-to-face communication but also in comparison with other channels currently available in the business community (Montoya, Massey, Hung, \& Crips, 2009; Riordan \& Kreuz, 2010; Thomas, 2013). In the theoretical development known as Media Synchronicity Theory (Dennis, Fuller, \& Valacich, 2008), email is described as good for transferring information but inadequate for any kind of communication that involves relationship-building, such as persuasion, negotiation, and decision making. To obtain a good "fit," a rational manager would, then, choose a richer medium for sensitive or equivocal circumstances.

However, Markus (1994a, 1994b) found that a rational choice for managers in adopting a particular medium included the weighing up of other exigencies, such as getting a job done, or avoiding contact with group members who might object to the message, while they would ward off the negative effects of distance by "prophylactic telephone calls" (Markus, 1994b). More lately, a different angle has shown that on the contrary, concern for upholding the relationship is a factor that may induce a rational manager to choose email over face-to-face communication if the message is negative (Sheer, 2012; Sheer \& Chen, 2004), as the distance seems to ease the burden of embarrassment to both parties; similarly, for employees, email can serve to avoid awkward confrontation with a manager (Hastings \& Payne, 2013).

On the other hand, under the "cues-filtered-in" theories, the expectation would be that distance is lessened by the CMC users themselves. There is evidence that users encode and decode the socioemotional content in language to an extent that makes up for the lack of other cues both for the sender and the receiver, and that particularly for longer term associations, such as team work, the experience of CMC-supported groups is similar to that of face-to-face groups (Kock, 2001, 2004; Walther, 1992, 1995). Email used on a daily basis in a group may be enriched with relationship-building features like emoticons, and quick feedback can develop to resemble other synchronous channels (Thomas, 2013). Increasing the use of cues and the rate and amount of feedback in email therefore reduces the likelihood of miscommunication and inaccurate emotion perception between the senders and the receivers (Byron, 2008). 
It seems, then, that distance in itself is not necessarily a problem, but that contextual factors make different affordances relevant. In other words, it is not so much what a medium can do, as what users employ it for in a particular context; if they value distance and formality, they can choose to employ email as a decidedly lean medium. Accordingly, we propose to examine more closely the international users' goals in communication, and we propose that the range of goals hinges on the affordances of the medium.

Communication Media and Affordances. The theory of affordances has its origins in the work of ecological psychologist James Gibson (1986), who described affordances as the possibilities for action offered by an object or an environment to a perceiving subject. Affordances, therefore, represent the perceptions created and not a set of qualities of an object or an environment. Fayard and Weeks (2007) argued that the theory of affordances holds the promise of being a generally useful practice to study organizational behavior, in the sense of interpreting the interrelations between individuals and the environment they involved, and Zammuto, Griffith, Majchrzak, Dougherty, and Faraj (2007) found that the combinations of information technology and organizational practices can affect organizational form and function. Affordances such as virtual collaboration and mass collaboration, they argued, can act as bridging concepts, which emerge from the intersections of technology and organization systems. As they put it, "One cannot talk about a complex technology without reference to the social setting, just as it makes limited sense to talk about a door handle without discussing the people opening the open doors" (Zammuto et al., 2007, p. 753). Since affordances serve actors' purposes in the selected medium, it makes good sense to study the characteristics of the medium. We concur with Kupritz and Cowell (2011) that there are "objective aspects of communication channels that determine the availability of communication cues," and that it is a mistake to emphasize social context alone (p. 63); for business purposes, the communication cues interact not just with the social context but also with the organizational context, and both are necessary to establish communication goals.

The medium's possibilities may be obvious and shared by all users. In the case of email, for example, the generic property of asynchronicity is that it affords time to reflect, and where the copresence of a telephone conversation provides for goals like getting immediate feedback, asynchronicity provides for goals like being able to communicate at the sender's convenience. But perceived affordances may also be more tied to the subject's current goals, like ducking the responsibility for a particular action requested by an email, which is possible by the generic affordance of the forward function. Therefore, the enlarged notion of affordances represents the perceptions created and not just a set of properties of an object or an environment.

Affordances for cooperation. Email is used in business communication because of its efficiency, because the central generic properties for daily transactions facilitate cooperation. Louhiala-Salminen and Kankaanranta (2005) described the ease with which the business community can transfer large swathes of text (the "postman" genre), the informality and speed in asking and getting an answer (the "dialogue" genre), and the ease with which a number of people can be notified (the "pinboard" genre). Also, it is easy to involve a side audience via the $c c$ function, which is more targeted than the inclusive pinboard mails.

Furthermore, email allows the writers to keep a record of their exchanges, a quality highly prized in business (Jung \& Lyytinen, 2014), and to pace the interaction by formulating a text and revising it before pressing send-affordances that Dennis et al. (2008) call reviewability and revisability. The latter is of particular relevance for our study, as nonnative 
language users often rely on text-based media as their preferred choice (Klitmøller \& Lauring, 2013; Lee \& Panteli, 2010; Skovholt \& Svennevig, 2006), because telephone conversations require immediacy in terms of access to vocabulary and syntax, and high levels of comprehension. Instead, email allows nonnative writers to write with more clarity and accuracy (Kankaanranta \& Planken, 2010), and more correctly and politely (Duthler, 2006), and thus present a better self-image.

In sum, in the literature, the cooperative affordances in normal business relationships have been discussed as follows:

- Revision: allows the user to optimize information relevance and choose words.

- Review: allows the user to keep information to hand.

- Exchange: allows the user routine dialogue with quick questions and answers.

- Inclusion: allows the user to involve a group for information or approval.

Conflict potential. On the other hand, the use of email has been shown to give rise to both negative behavior and negative attributions (Byron, 2008; Davis, Leas, \& Dobelman, 2009; Lee \& Panteli, 2011; Turnage, 2007). One explanation could be that email presents different affordances to senders, who choose the medium for their own purposes, and receivers, who react.

Email usage in business environments shows certain tendencies. Leonardi, Neeley, and Gerber (2012) showed that managers in a position of power tend to go for efficiency ("When you've got a job that needs to be done you should just shoot an email," p. 108), assuming that the request will be carried out, thereby disregarding the lack of feedback and making assumptions in impoverished informational circumstances. Large amounts of content may be bundled into a message, whereby the turn-taking system in the electronic dialogue is abused and efficiency suffers; but again, from the receiver's point of view, it is an affordance to be able to strategically select a portion of the message to attend to in his or her answer (Friedman \& Currall, 2003).

Second, a style with more direct phrasing has been noted, which may be perceived as rude by recipients. Even the norm of casualness that surrounds email poses dangers, particularly for nonnative users. For example, significant pragmatic failure has been noticed by Economidou-Kogetsidis (2011), where media-induced directness is read as brashness by native speakers.

Third, the absence of social cues is particularly prone to induce mistrust where expectations between business partners are perceived to be infringed (Barry \& Crant, 2000). Where the recipient's cues-filtered-in are usually seen as part of the positive process of building group identity, in conflictual contexts reactions are often based on fear rather than hope, which results in the communicators laying the blame on the other party at the personal level, rather than on the situation itself (Baruch, 2005; Bazarova \& Walther, 2009; Cramton, Orvis, \& Wilson, 2007). Lack of context over geographical distance is a problem for absent receivers, as missing contextual information may lead to differently perceived salience of the message, and hence, failing to respond may lead to attributions of ill will or demonstrations of power (Cramton et al., 2007). For example, different norms for the expected speed of answer have been noted; thus in Klitmøller and Lauring (2013), the Europeans mention the different sensitivity to time and urgency that their Indian colleagues display in answering emails.

Finally, the copying feature of email creates an ambiguity in communication. While email copies in teams serve to share knowledge of ongoing projects, and to create a high level of ownership, the copying to a third party can also be useful for reasons of control among distributed workgroups, by putting pressure on the addressee to conform (Lee \& 
Panteli, 2010; Skovholt \& Svennevig, 2006), by increasing central power, by facilitating the building of coalitions, or by "playing the accountability game" (Markus, 1994b).

In sum, when social relations in the organization are (potentially) conflictual, email affordances include the following:

- Review: allows the user to retain evidence, for example, of promises made.

- Exchange: allows the user to

- assume dialogue effect on the basis of unilateral messages.

○ control the turn sequence, for example, by withholding a response.

- nourish negative attributions without the test of feedback.

- Inclusion: allows the user to hold the recipient accountable via $c c$ and forward.

This rather formidable list should discourage managers from the use of lean media if they are collaborating on a project of an ambiguous nature, with doubts whether they are competing or cooperating. However, seen through the lens of affordances, we notice some subtle possibilities to do with control, and ducking the attempts at control. If the managers are assumed to use communication to serve complex goals, like both getting things done and keeping channels open, while retaining control and legitimacy, then what appears at first sight as limitations will turn into affordances. For example, choosing email for a request serves the dual purposes of getting compliance from the receiver and simultaneously documenting due diligence.

However, all the strategies are also open to the receiver when he or she turns sender for the response. Among other things, a request can go unanswered, the original sender's polite minimization can be taken as an excuse for actively ducking the underlying obligation, information can be forwarded to a third party as a way of not resuming responsibility, and $c c$ can be used to put a conflict on record or make it escalate.

In sum, users may avail themselves of email affordances both to foster and exacerbate workplace conflict while retaining control. Before examining these affordances in actual use, we need to outline what we mean by conflict in this context.

Workplace Conflict. We follow de Dreu and Gelfand (2008) in defining workplace conflict as "a process that begins when an individual or group perceives differences and opposition between itself and another individual or group about interests and resources, beliefs, values or practices that matter to them" (p. 6). They single out as two of the root causes: scarce resources - conflicts of interest mostly as task conflicts - and social standing and the search for a positive view of the self-mostly as relationship conflicts (p. 8).

In the literature of conflict handling between individuals and groups, the majority distinguish three types of conflict responses, viz. collaborating, contending, and avoiding (for a recent overview, see Adair \& Loewenstein, 2013). The data for these studies most often derive from decision making or interdependent negotiation of a single agreement. However, a conflict of competition at the company level yields a somewhat more complex pattern, as the project managers compete for scarce resources, like time or delivery rights, while seeking to uphold their social standing vis-àvis both their own company and their intercompany development group. Thus, the background conflict at the 
organizational level can be a reasonably steady state for a long period, while single incidents will show responses that can be treated as collaborating, contending, or avoiding in the social context.

Avoidance. Avoidance has received some attention in the literature of international workplace conflict, particularly in relation to East Asia, where a body of literature leads us to expect that harmony is at a premium and hence avoidance is to be anticipated. Ohbuchi and Atsumi (2010) found that for Japanese respondents, "avoidance contributed to group harmony and interdependent identity while it hampered personal interests and fairness" (p. 117). Friedman, Chi, and Liu (2006) found more regard for the feelings of others in a conflict among Chinese than among Western subjects. Moreover, Keller and Loewenstein (2011) documented how behavior that counts as competition in the United States was not necessarily seen as such in China, thus leading to fuzziness in terms of in-group and out-group identity. When asked, Chinese subjects would declare that an option like "avoid" was for them cooperative, and failure to answer an email implied consultation and reflection, and that failing to compete was in itself uncooperative. Such insights are in line with the long-held view that in East Asia, more importance is attached to social presence, because of the intertwining of personal and business relationships (Carlisle \& Flynn, 2005; Chen, Huang, \& Sternquist, 2011; Dunning \& Kim, 2007; Gao, Ballantyne, \& Knight, 2010; Peng \& Tjosvold, 2011).

In accordance with Tjosvold and colleagues, we expect face-saving to play a large role in interorganizational conflict handling, with instances to fill categories like yielding, outflanking, delay, and passive aggression (Peng \& Tjosvold, 2011; Tjosvold \& Sun, 2002). Lean media have been seen as a preferred choice for general workplace conflict avoidance (Lauring \& Klitmøller, 2015; Sheer, 2012). However, we subscribe to the view put forward by Wang, Fink, and Cai (2012), that avoidance is a goal-directed behavior, and that different conflict goals lead to different avoidance strategies, particularly for participants with complex loyalties. We therefore expect that with a lean medium, a manager can balance competitive and cooperative goals, because the distance allows for postponement of any resolution to the conflict, while at the same time avoiding the assignment of blame.

\section{Methodology and Research Site}

This field study is ethnographic, in that it involves participant observation over time, a method that has been used extensively to obtain rich data. This entails an interpretive approach to understand the effects of both the technologically mediated and the socially constructed environment (Fayard \& Weeks, 2007). The research case used in this study follows Yin's recommendation that it should be a context that is not uncommon for its industry and conditions (Yin, 2014) so that, despite the fact that no hypothesis can be tested quantitatively, observations can be made which lend themselves to some degree of generalization.

The data were collected while the second author worked at the company's headquarters as a temporary engineer in the R\&D department for 6 months during 2007. She attended both formal and informal social activities, including meetings, telephone discussions, audio- and videoconferencing meetings, email communications, product seminars, and informal social activities. She recorded what she saw and wrote a daily log at the end of every workday to summarize what had occurred.

Furthermore, interviews were collected to allow the participants to reflect on their practices. Formal interviews were supplemented with unstructured interviews, as the question of media use came to include the sensitive topic of conflict; 
most of the members involved in the communication preferred to give instant, off-the-cuff feedback on their practices. For the more formal interviews, a list of predesigned topics was developed as a guide. The interviews were conducted with the key informants, including R\&D project managers and engineers from the focal company as well as managers and engineers from the supplier. Over and above the logs and transcribed interviews, the documentation includes email exchanges, meeting minutes, and other written sources. All interviewees and writers of the collected writing knew the purpose of the research and were guaranteed anonymity.

In this study, we shall concentrate on findings from three sources, viz. observation logs, interviews, and email documentation. Together they constitute the sort of data triangulation where multiple sources of evidence are collected to minimize the degree of distortion and to reduce the risk of arriving at abnormal conclusions brought about by the bias of data (Yin, 2014); the combination of the correspondence and the access to writers' and receivers' reactions provides a rare opportunity to observe the effects and attributions surrounding mediated communication in the workplace.

\section{Company Context}

The focal company, T-Tech, is a high-tech company headquartered in Taipei, Taiwan. At the time of study, it had about 3,000 employees. The strategic partner, KN, has its headquarters in Seoul, South Korea, and a branch office in Taipei. Internally, communication took place in Mandarin, whereas communication with KN was mainly in English and only secondarily Mandarin.

As mentioned above, T-Tech had recently entered the North American entertainment market, and generated over US $\$ 2$ billion in revenue within 2 years of its launch. $\mathrm{KN}$ also worked in the home entertainment market. Its big manufacturing unit supplied goods for several companies, including T-Tech. The competition between the two companies went on record when an industrial magazine revealed that a T-Tech-branded product had overtaken $\mathrm{KN}$ as the top brand in the North American market.

The relationship between $\mathrm{T}$-Tech and $\mathrm{KN}$ had been built around the purchase of a key component for electronic display equipment. This component was a complicated assembled part with intricate technological design, and there was a large amount of technological codesign activities involved in the buyer-supplier relationship. However, at this time, when the two companies introduced similar equipment in North America, control of the supply chain became important, since this component was new in the market with a number of pioneering techniques. Because there was no general design standard operating in the industry, the two companies worked under different standards, which led them to spend a great deal of effort in agreeing on design details.

The R\&D department comprised two managers and six engineers, and it had up to seven projects of varying magnitudes running at the time. They worked closely with the Purchasing department, as the new components were created through purchase and codevelopment. The department answered immediately to general management, with the VP for Production as their immediate superior. In the following examples, the central character is the manager we shall call Chen, as most of the conflict passed across his desk. There are also examples involving two of the engineers, Lee and Stephen, and a purchasing manager called Tony.

From the Supplier side, the examples quoted involve the departments of Sales and Customer Service. On the Sales side, we quote from the manager Shin, and in the Customer service Kevin and Bob. 
In all cases, the mails are selected for the affordances they illustrate. As our field of interest is interorganizational mixed-motive cooperation tinged with conflict, also known as "co-opetition" (Tsai, 2002), we limit our examination to those interactions between the two companies where individuals write to their opposite number as members of the production team and/or as managers in their respective companies.

\section{Findings}

In the following, we set out the findings arranged under the headings of the main affordances identified in our analysis.

Interestingly, the data sources complement each other, as the interviews yield different answers from the logs, particularly with regard to the use of communication media in conflict handling. Perhaps not surprisingly, the managers stress the cooperative use of email when they are interviewed, whereas they discuss the contending potential only as explanatory feedback in concrete situations. All names are pseudonyms, but their company functions are authentic.

\section{Revision}

In interviews managers stressed the affordance of revisability; they felt that the extra time helped forestall misunderstandings caused by telephone conversations:

1. [Interview with T-Tech project manager, Chen]:

I like to use email. Telephone discussion easily causes misunderstandings. If I have to discuss something urgently by phone, I write an email to confirm that we have the same understandings about the content on the phone. (. .) If the issues are too complicated to describe by emails, I prefer to hold a meeting to discuss the points face to face.

However, the collected workflow samples reveal that the preference for email was also based in another perceived affordance, that of time lag, for it appears from the logs that the preference was related to foreign language competence. Outside quotations, $I$ refers to the researcher. The logs are translated from Mandarin.

2. [Daily log involving R\&D engineer, Lee]:

I said to Lee, “This issue is urgent. Why don't you just make a call to them?” Lee answered, “This issue is sensitive. My English speaking is not good. If I don't explain it well on the phone, it could cause a big problem. ... I am still thinking how to explain the whole situation more clearly. Don't worry! I will write an email to them later."

The data show that for this project, the choice of the telephone was made only in exceptional cases, and when it was used, it was backed up with email to reinforce and clarify the message.

Admitting to difficulties with spoken English was seen as a task problem; however, the search for social standing and a positive view of the self can also be seen as a goal in circumstances where a telephone call was an option without a loss of face:

3. [Daily $\log ]$ : 
Chen was complaining while he was writing an email, "I really don't understand why Bob [KN's Customer Services manager] didn't have even a basic knowledge about the product." He then showed me the email that he was writing about the product pixel pitch calculation.

"Bob is usually very busy. You may wait for several days to get his email reply. Why not just call him? If he didn't understand the mistake, you can explain it to him, there and then," I said.

"I hate talking to him," Chen responded. "I may shout at him if he continues to speak in a tough way." I knew he had had arguments with Bob before, so I offered help, "Would you like me to call him to clarify the issue?" "Oh ... that would be great. Thank you."

We find that at T-Tech, email was valued for its distance and leanness. When asked formally, users referred to the affordances of forestalling misunderstandings, but in daily problem solving, they oriented to the need for face-saving, with protection from losing face from inadequate English and from suffering aggressive behavior. Thus, the affordance of revisability was associated with collaborating responses.

\section{Recordability}

The managers valued the reprocessable records; it appears from the logs that they were keenly aware that email gave them the written documentation they needed:

4. [Daily $\log ]$ :

Chen made a conditional approval for an order for next month. But KN accused Chen of being mistaken about the quantity of the conditional approval and thus the KN factory hadn't produced a sufficient number of goods for T-Tech. Chen turned around to me and said, “Could you find the emails which KN sent to us before [on this matter]?" I replied, "I didn't ask for an email from KN on this. She told me this by phone." Chen was mad and said, "I told you several times that we need EMAILS, EMAILS! You need to be really sensitive when working with KN. DO NOT trust oral information."

Chen himself wrote detailed emails to put on record the exact nature of his complaints:

5. [Mail from T-Tech project manager Chen to KN Sales Manager Shin]:

Dear Shin

We have just been informed that your company has delivered 3480pcs of Project no.50 "ver.T45" to our factory. However, I don't know when you started to change to "ver.T45." We won't accept them as we've only approved the "ver.T35."

This SD has caused much controversy: ROM data has just been updated on the T35, IM type has been approved for the T35 and the resolution for the SD shut down problem is under study for the T35. Therefore, we WILL NOT agree to you delivering the T45 without approval and without any resolution of the above problems.

Best regards, Chen

Reprocessable records are a valuable affordance for any business, but in case of a conflict, the particular goal served here was to be able to quote them back to the partner as accountability. More than ease in tracking records, then, the 
noticeable affordance here is to create records as a source of control, so that a confrontational response is backed up with legitimacy.

\section{Exchange}

Throughout the period, exchanges were used for cooperative purposes, with informal greetings and personal details, particularly among the R\&D staff. However, problematic communications were routinely forwarded to the project manager, who undertook the response. It is noticeable that ready-made polite phrases were often present in these transactions; they seem to serve the express purpose of upholding a ritual, thereby forestalling conflict:

6a. [Mail from KN manager Shin to T-Tech purchase manager Tony]:

Dear Tony!

I always appreciate your support.

KN has already internally started project \#46 MP preparation and we will start MP from next week. They are not for T-Tech but for another customer. So at the moment we cannot input T-Tech's request and have to wait till the week after. Thank you!

Shin

6b. [Mail from T-Tech, answering the text above, which was forwarded to Chen]:

Dear Shin

We fully understand the situation of tightening schedule pressures. Please try your best to help. Thank you for your great support.

Chen

Organizational responsibility for the project entailed having a social standing to defend, and time was a scarce resource. The combination was visible in cases where tardy and unsatisfactory email replies gave rise to negative attributions. In an incident where a T-Tech engineer, Stephen, had written repeatedly to extract a set of specifications, the response gave rise to explicit attributions:

7a. [Mail from KN Customer Services Kevin to T-Tech engineer Stephen]:

Dear Stephen

Thanks for your comment.

Even you developed new models, what we provide data to you were same.

=> EMI, Safety, MTBF, RoHS (But it's same), CAS (It also same spec. with IPM type)

I talked with our engineer about waveform but it's not related to your side. So I don't want to give any confusing to you.

I think you have enough data to check this ECN. Thanks!

Kevin

7b. [Daily log]: 
Chen, reading the email: "How can he [i.e., Kevin] predict that the data we'll need must be the same? He has no right to comment about it. Ask him which engineer told him that waveform is not related to our design! You should lecture him on why we need it. ... What?! Who does he think he is to tell us we have enough data to approve this ECN? ... The engineer's manner is so offensive."

It seems that the KN engineer was charged with arrogance in a situation where he might, possibly, just be guilty of misjudging the context and the salience of the information requested by T-Tech; the information shortcut, admissible between peers and teammates, was interpreted as a personal attitude problem. Delays and avoidance on the part of KN were explicitly construed as competitive tactics, but there is no evidence from interview comments that the managers were aware of the connection between the medium and their perception of the sender.

Exchanges, then, were used in conflictual circumstances to demonstrate the ritual of cooperative collegial relations, but the exchanges also carried the opportunity of group identification at the receivers' end; the users nourished sinister attributions, but they guarded their self-image by not putting the contending responses on record.

\section{Inclusion}

Some actions taken, and documented with emails, were clearly meant for a secondary audience in the home organization:

8. [Daily $\log ]$ :

T-Tech had been waiting for KN's confirmation about the spec. controversy over project \#46 for two weeks. T-Tech's purchase manager was becoming impatient and called Chen to check the progress. He asked me to email KN requesting a meeting and said I must c.c. the purchase manager to let him know about KN's non-cooperative response. Thus, I sent an email to KN's Bob and Shin (and T-Tech's purchase manager was included in the c.c. list). This simply requested that we should hold a meeting.

Chen said to me that he didn't think that either Bob or Shin would attend the meeting, but he believed that the email would emphasize KN's lack of support.

Ostensibly, Chen cooperatively furthered the action that he was asked for, but his overriding goal with the $c c$ 's seems to be that of documenting due diligence and pass on the accountability, and at the same time fan the conflict by spreading the negative perception of the partners.

The corpus has one example of strategic use of indirect inclusion, which is at the same time an example of active avoidance. When yet another quality issue came up, T-Tech threatened to reject the entire shipment of a component called T45 if documentation was not forthcoming. KN sales staff sent a mail to say that they regarded the issue as already settled. Two days passed.

9. [Daily log]:

Chen does not reply to the email. "He sounded like he's done everything we need but he hasn't. The attached document he sent last time didn't mention anything about T45. . . It's not my fault if their products are rejected. . . I'd like to see how he's going to sort out this problem." 
Several more days passed with various mails from $\mathrm{KN}$ to which Chen did not reply. Eventually, the KN sales manager was forced to go up the chain of command and contact T-Tech's management, thus also presenting his original failure to meet a T-Tech demand. Chen's demonstration of power was aimed at a forum outside the development team, and very far from the cooperative attitude collected by Keller and Loewenstein (2011), that not answering an email represented "consultation and reflection." In practice, he sabotaged the turn-taking system to attract attention to the team-level conflict while avoiding any responsibility for it. The affordance of inclusion, then, is associated not just with accountability but also with strategic avoidance.

\section{Discussion}

The driving aim of this study has been to explore email affordances in strategic interorganisational relationships that experience conflict. Two particular email affordances emerged from our study: passive protection and active control.

\section{Passive Protection}

From the point of view of interorganizational conflict, it is interesting that the protection is apparently directed both toward the individual's need to safeguard his face and legitimacy vis-à-vis the partner-competitor, and also vis-à-vis his own management. This finding is qualitatively different from other results where CMC was found to serve the function of buffer or shield for communication of dissent of negative emotion (Riordan \& Kreuz, 2010; Turnage \& Goodboy, 2014). For example, the display of norm-upholding rituals is an affordance based in the positive, relationship-building function, but its related strategic effect is that it demonstrates to the receiver, and to possible others aware of the situation, that if relations break down, it is not the sender's fault.

This dual-purpose protection seems to us to support our opening claim, that email is a rational and effective choice also for equivocal transactions. With email it is possible to juggle different sets of goals with different logics.

These different logics can be isolated in the way the managers construe their different roles or workplace identities in this international collaboration. We have found purposes and goals related to four identifiable roles that the T-Tech senders undertake in this collaboration, roles whose salience differs according to the current purpose. Particularly for the manager Chen, we have demonstrated that he occupies different roles on a daily basis: (a) as nonnative language user, (b) as buyer with the supplier, (c) as project manager for the company, and (d) as colleague with a developing team.

The protection of the nonnative speaker concerns the face and legitimacy considerations that are closely linked to feelings of disempowerment, regarding which Neeley (2013) found that nonnative speakers of the company lingua franca, English, suffered a status loss and felt disempowered in dealing with their native-speaker colleagues. An asynchronous medium protects the user from being put on the spot and from feeling that he argues weakly.

For the buyer, the fear of losing control is a strong motivation for avoiding behavior. The seller occupies a position that customarily should engender a measure of deference, so when a buyer-manager says he is afraid that he may shout at a recalcitrant partner, he is clearly protecting his self-respect. At the same time, email facilitates competitive goals, for the confrontations about late or faulty deliveries are bald-on-record in a way which would have been difficult in a richer medium, but without the associated loss of face. 
In his role as project manager, the user is acting in his own organizational context, and here he is protected through his records. He is a boundary spanner who needs legitimacy both with the partner organization and at home, and in this role, we see a more proactive use of strategic avoidance. When a user $c c$ 's his own organization to expose the lack of cooperation on the part of the partner-competitor, without raising an actual complaint, which could be interpreted as if he himself was not an efficient manager, the strategy recalls what Tjosvold and Sun (2002) termed outflanking. The user involves higher authority while retaining apparent blamelessness.

Finally, the colleague is protected through the social email norm of informal messages with greetings and personal remarks between engineers, supplemented with ritual courtesy to cushion demands and excuses between managers, who handle the conflictual part of the communication. Hence, while users may talk about a partner in distrustful and denigrating terms around the office, the emails contain courtesy of the sort that comes ready-made for such exchanges, but it would be difficult to carry out in conversation.

\section{Active Control}

The findings show that users avail themselves of email options that allow them to strategically select responses, and this often co-occurs with options that serve goals of protection. For the manager in his role of nonnative speaker, he is afforded control of the formulation of technically demanding information. In his role as buyer, because of the contractual power hierarchy, he can avail himself of the option of one-sided monologue to issue demands and protests and expect to have them acted on, and he can store the records for future reference in the accountability game. As a manager in his own company context, he can control the spread of information about the collaboration.

However, just as different goals can be served simultaneously, different logics may collide. Thus, the findings show that a task conflict about scarce resources (in this case, faulty and tardy documentation) is overruled by a relationship conflict of social standing (emails dealing with the situation that go unanswered, in order to force the partner to assume accountability to an important audience). Where one logic prompts use of the email affordance for efficiency in problem solving for the sake of the company, a different logic prompts the user to block the process to achieve the personal satisfaction of punishment.

\section{Conclusions and Implications}

On the basis of the findings, we conclude that the answer to our research question, regarding what affordances there are for email users in interorganizational collaboration, is twofold.

Our first conclusion is that all the groups of affordances that we isolated above are used partly for protection, and partly for control, but we find no one-to-one correspondence between a kind of perceived affordance and a particular kind of conflict response. The second conclusion is that there is more explanatory power in the communicative roles or situated identities assumed by the communicators in context, as these seem to be of significance for the affordances that they avail themselves of. Thus, in this kind of steady low-key conflict, where competition at the organizational level is played out in varying episodes of conscious conflict amid the daily business of production at the team level, the lean medium has been demonstrated to furnish users with options for both contending, collaborating, and avoiding uses, depending on the mixture of user's goals. 
With this study, we set out to forge a link between organizational behavior and media affordances. We have demonstrated the effect of conflict in the focal managers' communication, both laterally and upward, through observation and collected examples rather than survey responses. In so doing, we have mapped a little-known relationship between CMC and strategic purposes in a business relationship. To our knowledge, the documenting of attitudes and reactions surrounding the sending and reception of company emails is new in the literature.

Future research with access to both the communication and its environment would be particularly fruitful in the area of intercultural relationships, where the element of conflict is at present little understood. We hope to have shown that the addition of the recipient angle constitutes a much-needed reality check, which is normally lacking in studies conducted by survey or through written documentation only.

We believe the study has implications for international partners who may wish to forestall and handle task and relationship conflicts, in so far as they relate to media use. Thus, areas for further research include the influence of communication technology on social interactions within multilingual teams in organizations, for whom global dispersal is the new reality.

\section{Declaration of Conflicting Interests}

The authors declared no potential conflicts of interest with respect to the research, authorship, and/or publication of this article.

\section{Funding}

This work was supported in part by the Ministry of Science and Technology of the Republic of China under the grant NSC 99WFD1000074.

\section{References}

Adair, W. L., \& Loewenstein, J. (2013). Talking it through. Communication sequences in negotiation. In M. Olekalns \& W. L. Adair (Eds.), Handbook of research on negotiation (pp. 311-331). Cheltenham, England: Edward Elgar. doi:10.4337/9781781005903.00022

Barry, B., \& Crant, J. M. (2000). Dyadic communication relationships in organizations: An attribution/expectancy approach. Organization Science, 11, 648-664.

Baruch, Y. (2005). Bullying on the net: Adverse behavior on e-mail and its impact. Information \& Management, 42, $361-371$. doi:10.1016/J.Im.2004.02.001

Bazarova, N. N., \& Walther, J. B. (2009). Attributions in virtual groups. Small Group Research, 40, $138-162$. doi:10.1177/1046496408328490

Brown, S. A., Dennis, A. R., \& Venkatesh, V. (2010). Predicting collaboration technology use: Integrating technology adoption and collaboration research. Journal of Management Information Systems, 27(2), 9-53. doi:10.2753/Mis0742-1222270201

Byron, K. (2008). Carrying too heavy a load? The communication and miscommunication of emotion by e-mail. Academy of Management Review, 33, 309-327. doi:10.2307/20159399

Carlisle, E., \& Flynn, D. (2005). Small business survival in China: Guanxi, legitimacy, and social capital. Journal of Developmental Entrepreneurship, 10(1), 79-96.

Chen, Z., Huang, Y., \& Sternquist, B. (2011). Guanxi practice and Chinese buyer-supplier relationships: The buyer's perspective. Industrial Marketing Management, 40, 569-580.

Cramton, C. D., Orvis, K. L., \& Wilson, J. M. (2007). Situational invisibility and attribution in distributed collaborations. Journal of Management, 33, 525-546. doi:10.1177/0149206307302549 
Culnan, M. J., \& Markus, M. L. (1987). Information technologies. In F. M. Jablin, L. L. Putnam, K. H. Roberts, \& L. W. Porter (Eds.), Handbook of organizational communication (pp. 420-443). Newbury Park, CA: Sage.

Daft, R. L., \& Lengel, R. H. (1986). Organizational information requirements, media richness and structural design. Management Science, 32, 554-571.

Darics, E. (2014). The blurring boundaries between synchronicity and asynchronicity: New communicative situations in work-related Instant Messaging. International Journal of Business Communication, 51, 337-358.

Davis, A. S., Leas, P. A., \& Dobelman, J. A. (2009). “Did you get my e-mail?” An exploratory look at intercultural business communication by e-mail. Multinational Business Review, 17(1), 73-98. doi:10.1108/1525383x200900004

de Dreu, C., \& Gelfand, M. J. (2008). Conflict in the workplace: Sources, functions, and dynamics across multiple levels of analysis. In C. de Dreu \& M. J. Gelfand (Eds.), The psychology of conflict and conflict management in organizations (pp. 3-54). London, England: Psychology Press.

Dennis, A. R., Fuller, R. M., \& Valacich, J. S. (2008). Media, tasks, and communication processes: A theory of media synchronicity. MIS Quarterly, 32, 575-600.

Dunning, J. H., \& Kim, C. (2007). The cultural roots of guanxi: An exploratory study. World Economy, 30, 329-341.

Duthler, K. W. (2006). The politeness of requests made via e-mail and voice-mail: Support for the hyperpersonal model. Journal of Computer-Mediated Communication, 11, 500-521. doi:10.1111/j.1083-6101.2006.00024.x

Economidou-Kogetsidis, M. (2011). "Please answer me as soon as possible": Pragmatic failure in non-native speakers' email requests to faculty. Journal of Pragmatics, 43, 3193-3215. doi:10.1016/j.pragma.2011.06.006

Fayard, A.-L., \& Weeks, J. (2007). Photocopiers and watercoolers: The affordances of informal interaction. Organization Studies, 28, 605-634. doi:10.1177/0170840606068310

Friedman, R., Chi, S.-C., \& Liu, A. L. (2006). An expectancy model of Chinese-American differences in conflict-avoiding. Journal of International Business Studies, 37(1), 76-91.

Friedman, R. A., \& Currall, S. C. (2003). Conflict escalation: Dispute exacerbating elements of e-mail communication. Human Relations, 56, 1325-1347. doi:10.1177/00187267035611003

Gao, H. Z., Ballantyne, D., \& Knight, J. G. (2010). Paradoxes and guanxi dilemmas in emerging Chinese-Western intercultural relationships. Industrial Marketing Management, 39, 264-272.

Gibson, J. (1986). The ecological approach to visual perception. Hillsdale, NJ: Erlbaum.

Hastings, S. O., \& Payne, H. J. (2013). Expressions of dissent in email. Qualitative insights into uses and meanings of organizational dissent. Journal of Business Communication, 50, 309-331.

Jung, Y., \& Lyytinen, K. (2014). Towards an ecological account of media choice. Information Systems Journal, 24, $271-293$. doi:10.1111/isj.12024

Kankaanranta, A., \& Planken, B. (2010). Belf competence as business knowledge of internationally operating business professionals. Journal of Business Communication, 47, 380-407.

Keller, J., \& Loewenstein, J. (2011). The cultural category of cooperation: A cultural consensus model analysis for China and the United States. Organization Science, 22, 299-319.

Klitmøller, A., \& Lauring, J. (2013). When global virtual teams share knowledge: Media richness, cultural difference and language communality. Journal of World Business, 48, 398-406. doi:10.1016/j.jwb.2012.07.023

Kock, N. (2001). Compensatory adaptation to a lean medium: An action research investigation of electronic communication in process improvement groups. IEEE Transactions on Professional Communication, 44, 267-285.

Kock, N. (2004). The Psychobiological medium: Towards a new theory of computer-communication based on Darwinian evolution. Organizational Science, 15, 327-348. doi:10.1287/orsc.1040.0071

Kupritz, V. W., \& Cowell, E. (2011). Productive management communication: Online and face-to-face. International Journal of Business Communication, 48(1), 54-82. doi:10.1177/0021943610385656 
Lauring, J., \& Klitmøller, A. (2015). Corporate language-based communication avoidance in MNCs: A multi-sited ethnography approach. Journal of World Business, 50, 46-55. doi:10.1016/j.jwb.2014.01.005

Lee, J. Y. H., \& Panteli, N. (2010). Business strategic conflict in computer-mediated communication. European Journal of Information Systems, 19, 196-208. doi:10.1057/ejis.2010.4

Lee, J. Y. H., \& Panteli, N. (2011). You got email! The cases of inter-organizational collaboration for engineering product design. Engineering Management Journal, 23(3), 18-21.

Leonardi, P. M., Neeley, T. B., \& Gerber, E. M. (2012). How managers use multiple media: Discrepant events, power, and timing in redundant communication. Organization Science, 23, 98-117. doi:10.1287/orsc.1110.0638

Louhiala-Salminen, L., \& Kankaanranta, A. (2005). "Hello Monica, kindly change your arrangements": Business genres in a state of flux. In P. Gillaerts \& M. Gotti (Eds.), Genre variation in business letters (pp. 55-84). Bern, Switzerland: Peter Lang.

Markus, M. L. (1994a). Electronic mail as the medium of managerial choice. Organization Science, 5, 502-527. doi:10.1287/orsc.5.4.502

Markus, M. L. (1994b). Finding a happy medium: Explaining the negative effects of electronic communication on social life at work. ACM Transactions on Information Systems (TOIS), 12, 119-149.

Maruping, L. A., \& Agarwal, R. (2004). Managing team interpersonal processes through technology: A task-technology fit perspective. Journal of Applied Psychology, 89, 975-990. doi:10.1037/0021-9010.89.6.975

Montoya, M., Massey, A., Hung, Y., \& Crips, C. (2009). Can you hear me now? Communication in virtual product development teams. Journal of Product Innovation Management, 26, 139-155.

Neeley, T. B. (2013). Language matters: Status loss and achieved status distinctions in global organizations. Organization Science, 24, 476-497. doi:10.1287/orsc.1120.0739

Ohbuchi, K.-I., \& Atsumi, E. (2010). Avoidance brings Japanese employees what they care about in conflict management: Its functionality and "good member" image. Negotiation and Conflict Management Research, 3, 117-129.

Peng, A. C., \& Tjosvold, D. (2011). Social face concerns and conflict avoidance of Chinese employees with their Western or Chinese managers. Human Relations, 64, 1031-1050. doi:10.1177/0018726711400927

Riordan, M. A., \& Kreuz, R. J. (2010). Emotion encoding and interpretation in computer-mediated communication: Reasons for use. Computers in Human Behavior, 26, 1667-1673.

Sheer, V. (2012). Does e-mail facilitate negative performance feedback giving? Supervisor and subordinate responses compared via the concept of social accountability. Communication Studies, 63, 220-242. doi:10.1080/10510974.2011.633150

Sheer, V., \& Chen, L. (2004). Improving media richness theory: A study of interaction goals, message valence, and task complexity in manager-subordinate communication. Management Communication Quarterly, 18, 76-93. doi:10.1177/0893318904265803

Skovholt, K., \& Svennevig, J. (2006). E-mail copies in workplace interaction. Journal of Computer-Mediated Communication, 12, 42-65. doi:10.1111/j.1083-6101.2006.00314.x

Thomas, E. (2013). Supplier integration in new product development: Computer mediated communication, knowledge exchange and buyer performance. Industrial Marketing Management, 42, 890-899.

Tjosvold, D., \& Sun, H. F. (2002). Understanding conflict avoidance: Relationship, motivations, actions, and consequences. International Journal of Conflict Management, 13, 142-164.

Tsai, W. (2002). Social structure of "Coopetition" within a multiunit organization: Coordination, competition, and intraorganizational knowledge sharing. Organization Science, 13, 179-190.

Turnage, A. K. (2007). E-mail flaming behaviors and organizational conflict. Journal of Computer-Mediated Communication, 13(1), 43-59. doi:10.1111/j.1083-6101.2007.00385.x

Turnage, A. K., \& Goodboy, A. K. (2014). E-mail and face-to-face organizational dissent as a function of leader-member exchange status. International Journal of Business Communication. Advance online publication. doi:10.1177/2329488414525456 
van den Hooff, B., Groot, J., \& de Jonge, S. (2005). Situational influences on the use of communication technologies: A metaanalysis and exploratory study. Journal of Business Communication, 42, 4-27.

Walther, J. B. (1992). Interpersonal effects in computer-mediated interaction. A relational perspective. Communication Research, 19, 52-90. doi:10.1177/009365092019001003

Walther, J. B. (1995). Relational aspects of computer-mediated communication: Experimental observations over time. Organization Science, 6, 186-203. Retrieved from www.jstor.org/stable/2635122

Walther, J. B. (2013). Affordances, effects, and technology errors. In C. Salmon (Ed.), Communication yearbook 36 (pp. 190-193). New York, NY: Routledge.

Walther, J. B., \& Parks, M. R. (2002). Cues filtered out, cues filtered in. Computer-mediated communication and relationships. In M. L. Knapp \& J. A. Daly (Eds.), Handbook of interpersonal communication (3rd ed., pp. 529-563). Thousand Oaks, CA: Sage.

Wang, Q., Fink, E. L., \& Cai, D. A. (2012). The effect of conflict goals on avoidance strategies. Human Communication Research, 38, 222-252. doi:10.1111/j.1468-2958.2011.01421.x

Yin, R. K. (2014). Case study research. Design and methods (5th ed.) Los Angeles, CA: Sage.

Zammuto, R. F., Griffith, T. L., Majchrzak, A., Dougherty, D. J., \& Faraj, S. (2007). Information technology and the changing fabric of organization. Organization Science, 18, 749-762.

\section{Author Biographies}

Anne Marie Bülow is a professor at the Copenhagen Business School, Department of International Business Communication, where she heads the research group in international organizational communication, and teaches interpersonal interaction and negotiation processes.

Joyce Y.H. Lee is an assistant professor of Information Management and a research member in the Innovation Center for Big Data and Digital Convergence at Yuan-Ze University. She has wide-ranging experience in industry related to international business collaboration. Her current research interests include virtual alliances, online communication behavior and cross-cultural communication.

Niki Panteli is a professor of Information Systems at the School of Management at Royal Holloway University of London. Her current research focuses on collaboration and leadership within virtual teams and online communities. She serves on the editorial boards of Information Technology \& People and New Technology, Work and Employment. 